\title{
VARIAÇÃO INTRAESPECÍFICA NA ANATOMIA DO LENHO DE Hevea brasiliensis (Willd. ex A. Juss.) Mull. Arg. RELACIONADA À EXTRAÇÃO DE LÁTEX
}

\author{
Letícia Maria Alves Ramos ${ }^{1}$, João Vicente de Figueiredo Latorraca², Helena Regina Pinto Lima ${ }^{3}$, Glaycianne \\ Christine Vieira dos Santos ${ }^{1}$ \\ ${ }^{1}$ Universidade Federal Rural do Rio de Janeiro, Programa de Pós-graduação em Ciências Ambientais e Florestais, Seropédica, Rio de \\ Janeiro, Brasil - leticiaalves.ramos@ hotmail.com*, annechristine.santos@hotmail.com \\ ${ }^{2}$ Universidade Federal Rural do Rio de Janeiro, Departamento de Produtos Florestais, Seropédica, Rio de Janeiro, Brasil - \\ latorraca@hotmail.com \\ ${ }^{3}$ Universidade Federal Rural do Rio de Janeiro, Departamento de Botânica, Instituto de Ciências Biológicas e da Saúde, UFRRJ, Seropédica, \\ Rio de Janeiro, Brasil - limarural63@gmail.com
}

Recebido para publicação: 02/10/2017 - Aceito para publicação: 29/11/2017

\begin{abstract}
Resumo
Neste trabalho, foi estudada a influência da exploração do látex na anatomia do lenho de seringueiras nativas. Avaliou-se a hipótese de que as características anatômicas são afetadas pela atividade de extração do látex. Para isso, foram coletadas, de forma não-destrutiva, amostras em árvores nativas exploradas e não exploradas. As coletas foram feitas na Reserva Experimental de Catuaba, localizada em Senador Guiomard (AC). A estrutura anatômica do lenho foi analisada, sendo avaliados: o comprimento das fibras (não-gelatinosas e gelatinosas); diâmetro total e diâmetro do lume de fibras não-gelatinosas; diâmetro e frequência dos elementos de vaso; largura, altura e frequência de raios; e a proporção de tecidos. Árvores exploradas e não-exploradas diferiram na estrutura anatômica em relação às características quantitativas. Apenas as variáveis comprimento de fibra gelatinosa, diâmetro do lume das fibras, frequência de raios e proporção de elementos de vaso e raios não apresentaram diferenças significativas pelo teste de Mann-Whitney. Os resultados mais contundentes consistiram em aumento da largura e altura de raios nas árvores extraídas, bem como maiores proporções de fibras gelatinosas nas árvores não-extraídas. As diferenças observadas entre os grupos avaliados podem ser atribuídas à demanda de carboidratos que a regeneração do fluxo de látex ocasiona nesses indivíduos. Recomendam-se maiores estudos acerca do consumo de carboidratos não-estruturais, relacionados diretamente às mudanças na estrutura do xilema de seringueira.

Palavras-chave: Seringueira nativa, largura de raios, fibras gelatinosas.
\end{abstract}

\begin{abstract}
Intra-specific variation in the anatomy of Hevea brasiliensis (Willd. Ex A. Juss.) Mull. Arg. related to tapping activity. The influence of tapping on the wood anatomy of naturally grown rubber trees was studied in this paper. The hypothesis that anatomical characteristics are affected by tapping activity was evaluated. Thus, nondestructive samples were collected from tapped and untapped native trees. Sampling was carried out at Catuaba Experimental Reserve, located in Senador Guiomard (state od Acre, Brazil). The wood anatomical structure was analyzed, and the following features were assessed: fiber length (non-gelatinous and gelatinous); total fiber diameter and lume diameter of non-gelatinous fiber; tangential diameter and frequency of vessel elements; width, height and frequency of rays; and tissue proportion. Tapped and untapped trees differed in anatomical structure in terms of quantitative characteristics. Only the following variables did not show significant differences by the Mann-Whitney test: gelatinous fiber length; fiber lumen diameter; frequency of rays; and proportion of vessel elements and rays. The most remarkable results were the increasing width and height of rays in tapped trees, as well as the greater proportions of gelatinous fibers in untapped trees. The differences observed between the evaluated groups may be attributed to the carbohydrate demand that the regeneration of latex flow causes in these individuals. Further studies on the non-structural carbohydrate intake directly related to changes in the structure of the rubber tree xylem are strongly recommended.
\end{abstract}

Keywords: Native rubberwood, ray width, gelatinous fibers.

\section{INTRODUÇÃO}

A seringueira (Hevea brasiliensis (Willd. ex A. Juss.) Müll. Arg.) é uma espécie que ocorre naturalmente na Amazônia brasileira e em países vizinhos. Ela tem sido plantada em áreas tropicais com o objetivo de extrair látex para a fabricação de borracha (NOBUCHI et al., 2011). Recentemente, têm-se desenvolvido clones, visando à produção de madeira (NOBUCHI et al., 2011; SAFFIAN et al., 2014). No entanto, a colheita de madeira

FLORESTA, Curitiba, PR, v. 48, n. 2, p. 255-264, abr/jun 2018

Ramos. L. M. A et.al.

ISSN eletrônico 1982-4688

DOI: $10.5380 /$ rf.v48 i2.55584 
de seringueiras em florestas naturais, primitivas ou regeneradas é proibida de acordo com o Art. 29 do Decreto ${ }^{\circ}$ 5.975, de 30 de novembro de 2006 (BRASIL, 2006).

A influência da extração de látex no crescimento e propriedades da madeira de seringueira tem sido estudada a fim de se avaliarem os impactos dessa atividade no fluxo de látex e assimilados, em decorrência de alterações na recuperação da casca que foi removida (SILPI et al., 2006; SILPI et al., 2007; JUNJITTAKARN et al., 2012; SEVERO et al., 2013). Experimentos com plantas submetidas a métodos de extração, ou sangria, são importantes para uma melhor compreensão dos reflexos dessa atividade nas características do xilema, uma vez que a remoção parcial da casca obstrui a translocação de assimilados (SILPI et al., 2006; SILPI et al., 2007).

A drenagem do látex pode diminuir o crescimento da planta, pois a regeneração de seu fluxo consome carboidratos que poderiam ser utilizados para o crescimento (SILPI et al., 2007). Com essa atividade, cria-se uma demanda adicional que desvia o carboidrato das atividades normais para a regeneração do látex, evidenciada pela grande concentração de amido encontrada no lenho dessas árvores (SILPI et al., 2007). A regeneração do fluxo de látex entre as drenagens depende do influxo de carboidratos (primariamente a sacarose) dos elementos de tubo crivado do floema condutor (EVERT, 2006).

Novos elementos do tubo crivado, diferenciados na regeneração da casca, apresentam maiores diâmetros que os produzidos pelo câmbio na área não sangrada. Portanto, uma reorientação qualitativa no funcionamento do câmbio poderia contribuir para o decréscimo na produção de madeira (SILPI et al., 2006). Além disso, ferimentos no câmbio podem levar a diversas reações, dependendo da profundidade e extensão, tais como a compartimentalização da área afetada pelo bloqueio de vasos por tilos, ou produzida pelas células de parênquima radial, na região adjacente à afetada pela injúria. Nesse contexto, mudanças no conteúdo das células parenquimáticas durante as reações do câmbio oferecem informações sobre essas reações (NAKABA et al., 2016).

Neste trabalho, a influência da exploração do látex na anatomia do lenho de seringueiras nativas foi estudada, avaliando-se a hipótese de que as características anatômicas quantitativas são afetadas pela exploração do látex. Teve-se como objetivo identificar quais alterações anatômicas que ocorrem no xilema são provocadas pela exploração.

\section{MATERIAL E MÉTODOS}

\section{Área de estudo e amostragem}

Foram coletadas quatro amostras radiais do lenho de 10 seringueiras nativas da Reserva Experimental de Catuaba, localizada em Senador Guiomard (AC). Cinco destas árvores passaram por exploração do látex. As amostras foram obtidas de forma não destrutiva através de trado de incremento de $5 \mathrm{~mm}$ de diâmetro, com inserção da ferramenta na altura do peito (DAP). As amostras coletadas foram tombadas na xiloteca do Instituto de Florestas da Universidade Federal Rural do Rio de Janeiro (IF-UFRRJ) (Tabela 1).

Tabela 1. Relação dos indivíduos analisados e seus respectivos números de registro na xiloteca do IF-UFRRJ. Table 1. List of specimen and their respective registry number on the wood library of IF-UFRRJ.

$\mathbf{N}^{\circ}$ de registro

$\begin{array}{lc}7642 ; 7643 ; 7644 ; 7645 & \text { I } \\ 7646 ; 7647 ; 7648 ; 7649 & \text { II } \\ 7650 ; 7651 ; 7652 ; 7653 & \text { III } \\ 7654 ; 7655 ; 7656 ; 7657 & \text { IV } \\ 7658 ; 7659 ; 7660 ; 7661 & \text { V } \\ 7662 ; 7663 ; 7664 ; 7665 & \text { VI } \\ 7666 ; 7667 ; 7668 ; 7669 & \text { VII } \\ 7670 ; 7671 ; 7672 ; 7673 & \text { VIII } \\ 7674 ; 7675 ; 7676 ; 7677 & \text { IX } \\ 7678 ; 7679 ; 7680 ; 7681 & \text { X }\end{array}$

\section{Análises anatômicas}

Preparo das amostras

Cortes histológicos com espessura média de $18 \mu \mathrm{m}$ a partir de amostras da região intermediária entre a medula e a casca foram obtidos com o auxílio de um micrótomo de deslize (MICRON HM 450). Foram obtidos cortes histológicos orientados nos planos de corte transversal (ST), longitudinal tangencial (SLT) e longitudinal radial (SLR). O material remanescente dos cortes histológicos foi dissociado em solução aquecida de ácido acético glacial e peróxido de hidrogênio (1:1) por aproximadamente 12 horas. Os cortes histológicos e os tecidos 
dissociados foram tratados numa solução aquosa de safranina 1\% e de azul de astra 1\% (6:4) (BUKATSCH, 1972) para a montagem de lâminas semipermanentes.

Dimensões celulares e proporção de tecidos

Imagens digitais foram obtidas com o auxílio de uma câmera acoplada num microscópio óptico Olympus CX40 para medição do diâmetro tangencial dos elementos de vaso e determinação da proporção de elementos anatômicos. A partir de imagens do plano longitudinal tangencial, foram mensuradas a largura, altura e frequência de raios. Com o material macerado, foram mensurados o comprimento e a largura das fibras gelatinosas (quando presentes), comprimento, largura e diâmetro do lume de fibras não-gelatinosas. As mensurações seguiram os parâmetros estabelecidos pelas normas da IAWA Comitee (1989), com adaptações.

Análise estatística

Com os dados obtidos, foi realizada estatística descritiva, seguida do teste de Mann-Whitney, para verificar a distribuição dos dados das variáveis analisadas entre os grupos de árvores exploradas e árvores nãoexploradas. Ainda, foram avaliadas associações entre as variáveis anatômicas dos grupos estudados por análise de cluster em duas etapas (Two Step Cluster) e Escalonamento Multidimensional (EMD). Para isso, foi utilizado o software IBM SPSS Statistics@.

A análise de cluster procedeu-se segundo o Critério de Informação Bayesiana (BIC), utilizando a probabilidade de log como medida de distância. A significância das variáveis dentro dos clusters foi testada pelo teste de Bonferroni T-Student, ao nível de 95\% de confiança. O Escalonamento Multidimensional foi realizado a partir de entradas métricas (dados quantitativos), utilizando algorítimo PROXCAL a partir de matrizes de dissimilaridade.

\section{RESULTADOS}

\section{Características comuns}

Os indivíduos de seringueira apresentaram, independentemente do grupo avaliado, as seguintes características: camadas de crescimento pouco distintas (Figura 2A); elementos de vaso em arranjo radial, solitários ou em grupos de 2 ou mais elementos com seção circular a oval (Figuras 1A e 1B); placa de perfuração simples (Figura 2G); pontoações intervasculares pequenas, alternas; fibras não septadas, fibras gelatinosas presentes (Figuras 1A, 1B, 2C, 2E); parênquima axial apotraqueal em faixas estreitas, por vezes reticulado (Figuras $2 \mathrm{~A}$ e $2 \mathrm{~B}$ ), em séries de até 8 ou mais células; paratraqueal escasso; raios multisseriados (Figuras 1C e 1D), heterogêneos, com células do corpo do raio procumbentes com até 2 camadas de células marginais quadradas e eretas (Figuras 1E e 1F); raios fusionados (pouco frequente); presença de cristais prismáticos; e inclusões minerais de cristais prismáticos presentes em células de parênquima axial, radial (Figura 2H), e em tilos (Figuras 2B).

FLORESTA, Curitiba, PR, v. 48, n. 2, p. 255-264, abr/jun 2018

Ramos. L. M. A et.al.

ISSN eletrônico 1982-4688

DOI: $10.5380 /$ rf.v48 i2.55584 

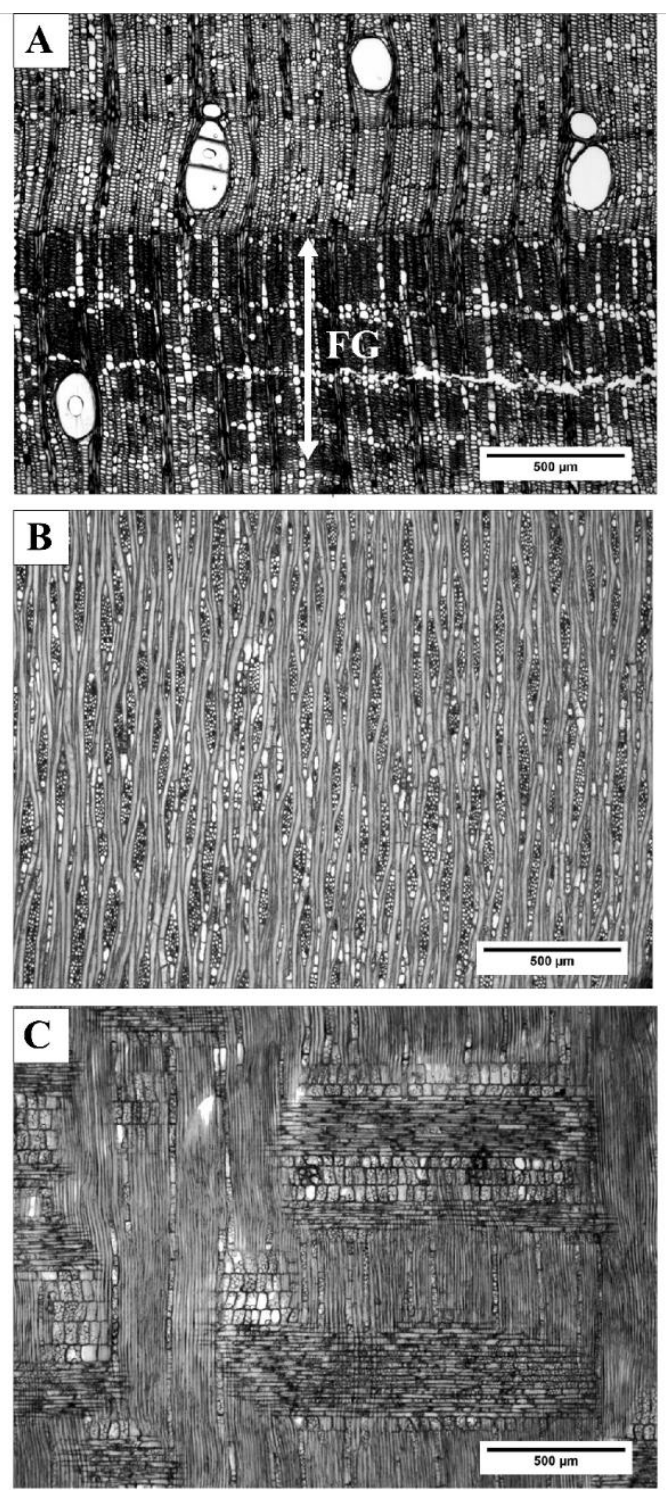

Figura 1. Anatomia da madeira de Hevea brasiliensis. A: Plano transversal, mostrando região com presença de fibras gelatinosas (FG); B: plano tangencial; $\mathrm{C}$ : plano radial, mostrando a presença de raios heterogêneos.

Figure 1. Wood anatomy of Hevea brasiliensis. A: transversal plane, showing region with gelatinous fibers (FG); B: tangential plane; $\mathrm{C}$ : radial plane, showing the presence of heterogeneous ratios. 

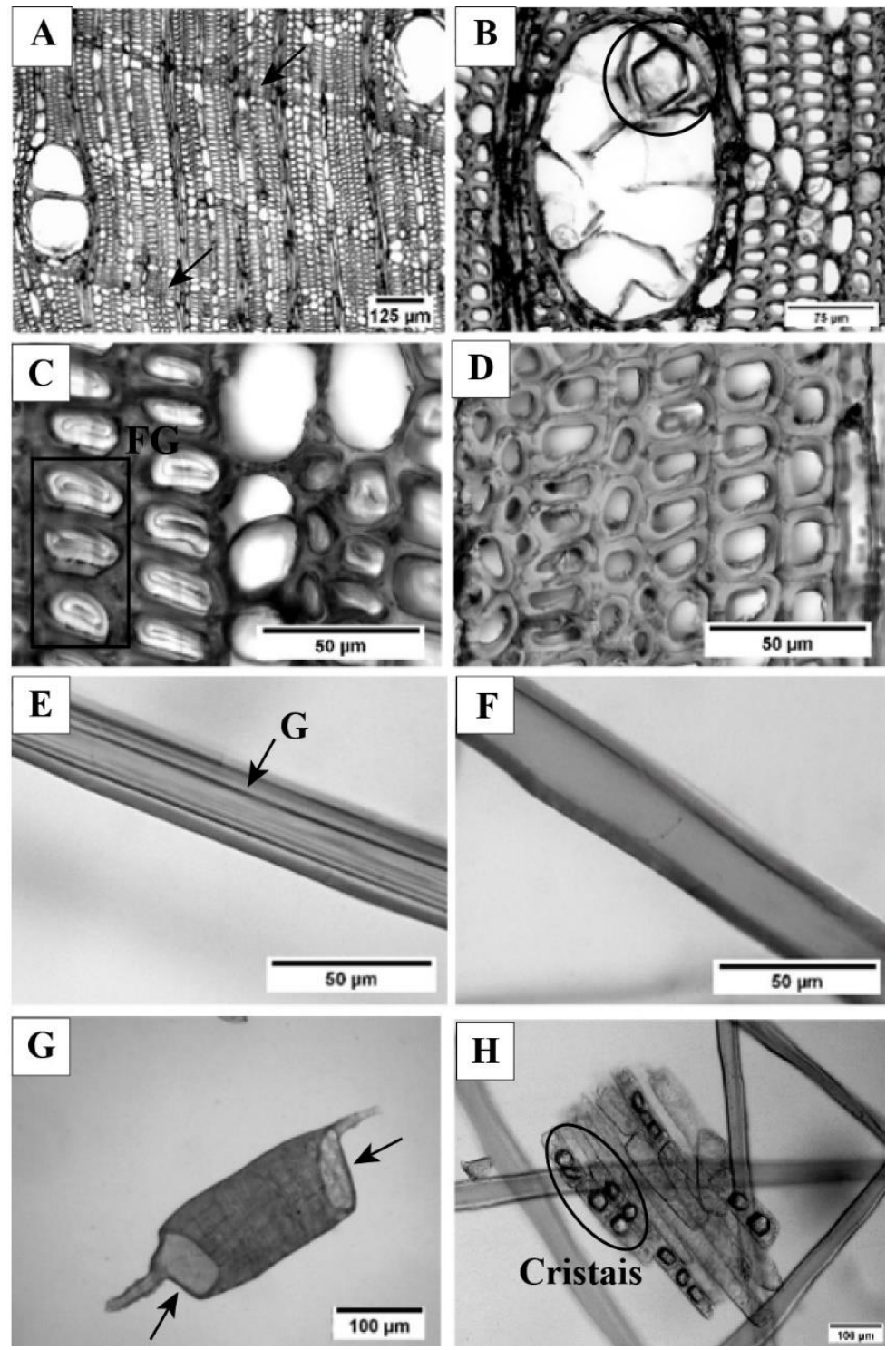

Figura 2. Caraterísticas comuns aos grupos de indivíduos de Hevea brasiliensis estudados. A: camadas de crescimento pouco distintas; B: cristais em tilos; C: fibras gelatinosas no plano transversal; D: fibras normais; E: fibra gelatinosa dissociada; F: fibra normal dissociada; G: elemento de vaso dissociado, evidenciando a placa de perfuração simples; H: células dissociadas de parênquima radial contendo cristais.

Figure 2. Common characteristics to the studied groups of Hevea brasiliensis. A: slightly distinct growth layers; B: crystals in tylosis; C: gelatinous fiber in the transverse plane; D: non-gelatinous fibers; E: dissociated gelatinous fiber; F: dissociated non-gelatinous fiber; G: dissociated vessel elements, evidencing simple perforated plate; $\mathrm{H}$ : dissociated cells of radial parenchyma containing crystals.

\section{Dimensões celulares e proporção de tecidos}

Na tabela 2, observam-se as médias e medianas para as 15 características anatômicas avaliadas. As variáveis do lenho apresentaram diferenças estatísticas entre árvores exploradas e não-exploradas pelo teste de Mann-Whitney, com exceção das variáveis comprimento de fibra gelatinosa; diâmetro do lume das fibras; frequência de raios e proporção de elementos de vaso e raios.

As fibras não-gelatinosas de árvores não-exploradas apresentaram médias de suas dimensões comprimento $(1266 \mu \mathrm{m} \pm 153)$, largura $(32 \mu \mathrm{m} \pm 6)$ e espessura de parede $(5 \mu \mathrm{m} \pm 1)$ - ligeiramente maiores que as dimensões das árvores exploradas (1244 $\mu \mathrm{m} \pm 153 ; 30 \mu \mathrm{m} \pm 5 ; 22 \mu \mathrm{m} \pm 5$, respectivamente). As fibras gelatinosas, por sua vez, não foram abundantes em ambas as situações analisadas. Quando presentes, apresentaram comprimento maior que o comprimento das fibras não-gelatinosas.

FLORESTA, Curitiba, PR, v. 48, n. 2, p. 255-264, abr/jun 2018

Ramos. L. M. A et.al.

ISSN eletrônico 1982-4688

DOI: $10.5380 /$ rf.v48 i2.55584 
Os indivíduos explorados apresentaram maiores largura e altura de raios, e maior proporção de parênquima axial. Quanto às médias do diâmetro tangencial de vasos e porosidade, observa-se maior diâmetro e menor porosidade para as árvores não exploradas.

Tabela 2. Parâmetros quantitativos do lenho de Hevea brasiliensis nos dois grupos avaliados. Letras diferentes indicam diferenças significativas entre os valores pelo teste de Mann-Whitney para $\alpha=0,05$.

Table 2. Quantitative parameters of Hevea brasiliensis wood in both groups evaluated. Different letters indicate significant differences among the values according to the Mann-Whitney test for $\alpha=0.05$.

\begin{tabular}{|c|c|c|c|c|c|c|c|c|c|c|c|c|c|c|c|c|}
\hline \multirow{3}{*}{\multicolumn{2}{|c|}{ Grupo }} & \multicolumn{15}{|c|}{ VARIÁVEIS ANATÔMICAS } \\
\hline & & \multicolumn{5}{|c|}{ Fibras } & \multicolumn{2}{|c|}{ Elementos de vaso } & \multicolumn{3}{|c|}{ Raios } & \multicolumn{5}{|c|}{ Proporcionalidade Celular } \\
\hline & & $\mathrm{CF}$ & LF & DLF & EPF & CFG & DV & FV & LR & AR & FR & PR & PPA & $\mathrm{PV}$ & PFG & PFN \\
\hline \multirow{3}{*}{ 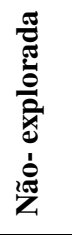 } & Mediana & $1262^{\mathrm{a}}$ & $30^{\mathrm{a}}$ & $21^{\mathrm{a}}$ & $5^{\mathrm{a}}$ & $1287^{\mathrm{a}}$ & $149^{\mathrm{a}}$ & $2^{\mathrm{a}}$ & $38^{\mathrm{a}}$ & $469,5^{\mathrm{a}}$ & $8^{\mathrm{a}}$ & $29^{\mathrm{a}}$ & $19^{\mathrm{a}}$ & $4^{\mathrm{a}}$ & $4,5^{\mathrm{a}}$ & $40^{\mathrm{a}}$ \\
\hline & Média & 1266 & 32 & 21 & 5 & 1318 & 146 & 2,5 & 38 & 481 & 8 & 29 & 19 & 4 & 13 & 35 \\
\hline & DP & 153 & 6 & 5 & 1 & 164 & 37 & 1 & 8 & 111 & 2 & 6 & 4 & 2 & 17 & 16 \\
\hline \multirow{3}{*}{ 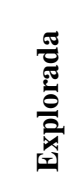 } & Mediana & $1240^{\mathrm{b}}$ & $30^{\mathrm{a}}$ & $22^{\mathrm{a}}$ & $4^{b}$ & $1300^{\mathrm{a}}$ & $142^{\mathrm{b}}$ & $3^{\mathrm{b}}$ & $47^{\mathrm{b}}$ & $509^{b}$ & $8^{\mathrm{a}}$ & $27^{\mathrm{a}}$ & $17^{b}$ & $4^{\mathrm{a}}$ & $0^{\mathrm{b}}$ & $48^{\mathrm{b}}$ \\
\hline & Média & 1244 & 30 & 22 & 4 & 1295 & $140^{\mathrm{b}}$ & $3,3^{\mathrm{b}}$ & 47 & 523 & 8 & 28 & 17 & 4 & 4 & 47 \\
\hline & DP & 153 & 5 & 5 & 1 & 137 & 31 & 2 & 9 & 121 & 1 & 5 & 4 & 2 & 9 & 11 \\
\hline
\end{tabular}

$\mathrm{CF}=$ Comprimento das fibras $(\mu \mathrm{m}) ; \mathrm{LF}=$ Largura das fibras $(\mu \mathrm{m}) ; \mathrm{DLF}=$ Diâmetro do lume das fibras $(\mu \mathrm{m}) ; \mathrm{EPF}=\mathrm{Espessura} \mathrm{da} \mathrm{parede} \mathrm{das}$ fibras $(\mu \mathrm{m}) ; \mathrm{CFG}=$ Comprimento de fibras gelatinosas; DV = Diâmetro dos Elementos de vaso $(\mu \mathrm{m})$; FV = Frequência de Elementos de Vaso $\left(\right.$ Vasos $\left./ \mathrm{mm}^{2}\right) ; \mathrm{LR}=$ Largura dos raios $(\mu \mathrm{m}) ; \mathrm{AR}=$ Altura dos raios $(\mu \mathrm{m}) ; \mathrm{FR}=$ Frequência de raios $($ Raios $/ \mathrm{mm}) ; \mathrm{PR}=\mathrm{Proporção} \mathrm{de} \mathrm{raios}(\%)$; PPA = Proporção de Parênquima Axial (\%); PV = Proporção de elementos de vaso (\%); PFG = Proporção de fibra gelatinosa (\%); PFN = Proporção de fibra não-gelatinosa $(\%)$

\section{Análise de agrupamento (Two Step Cluster)}

A análise Two Step Cluster distribuiu os dados em dois clusters, ou grupos, distintos em função das variáveis analisadas. O primeiro grupo representa as árvores não-exploradas, cujo tamanho corresponde a $46 \%$ dos dados, e o segundo grupo representa as árvores exploradas.

A Tabela 3 apresenta os centros de cluster, que são valores médios das variáveis que definem cada cluster. As variáveis analisadas foram classificadas de acordo com sua importância dentro dos clusters. Em ambos os clusters, a variável classificada como mais importante foi a largura de raios, seguida da proporção de fibras não gelatinosas.

$\mathrm{O}$ cluster 1 corresponde às árvores não-exploradas e caracteriza-se, principalmente, por: fibras ligeiramente mais compridas e largas, com parede celular mais espessa; vasos de maior diâmetro; raios mais finos e de menor altura; e maior proporção de fibras gelatinosas. O cluster 2 corresponde às árvores exploradas, caracterizado, principalmente, por: fibras ligeiramente menores e finas; raios mais largos e de maior altura; e menor proporção de fibras gelatinosas.

Tabela 3. Resumo da importância das variáveis anatômicas para a divisão dos clusters e os centros de cluster. Table 3. Summary of the importance of anatomical variables for cluster division and cluster centers.

\begin{tabular}{crcc}
\hline \multirow{2}{*}{$\begin{array}{c}\text { Ordem de } \\
\text { importância } \\
\text { geral }\end{array}$} & Variáveis & \multicolumn{2}{c}{ Cluster } \\
\cline { 3 - 4 } 1 & $* * *$ Largura de raios $(\mu \mathrm{m})$ & 1 - Não-Exploradas & 2 - Exploradas \\
2 & $* *$ Proporção de fibras não-gelatinosas $(\%)$ & 38.76 & 47.31 \\
3 & *Proporção de fibras gelatinosas $(\%)$ & 35.81 & 45.82 \\
4 & *Proporção de parênquima axial $(\%)$ & 12.11 & 4.31 \\
5 & *Espessura de parede das fibras $(\mu \mathrm{m})$ & 18.84 & 16.75 \\
6 & $*$ Frequência de elementos de vaso $\left(\operatorname{Vasos} / \mathrm{mm}^{2}\right)$ & 5.04 & 4.43 \\
7 & *Altura de raios $(\mu \mathrm{m})$ & 2.51 & 3.26 \\
& & 484.53 & 523.34
\end{tabular}




\section{Escalonamento multidimensional}

Na figura 3, é apresentado o mapa perceptual, ou seja, a representação gráfica dos espécimes de seringueira no espaço bidimensional, no qual os pontos representam os indivíduos explorados e não-explorados, agrupados a partir da análise das características anatômicas: largura de raios; proporção de fibras não gelatinosas, gelatinosas e de parênquima axial; espessura de parede; frequência de elementos de vaso; altura de raios; diâmetro de elementos de vaso; e largura das fibras.

Observa-se a existência de um padrão de agrupamento. Os indivíduos podem ser distribuídos em três grupos ao analisar a dimensão 1, em que: dois grupos são compostos apenas por indivíduos não-explorados, e um é composto apenas por indivíduos explorados. Cada grupo reuniu indivíduos com características similares entre si. A A9_E não compartilhou características similares para se inserir em nenhum dos grupos formados.

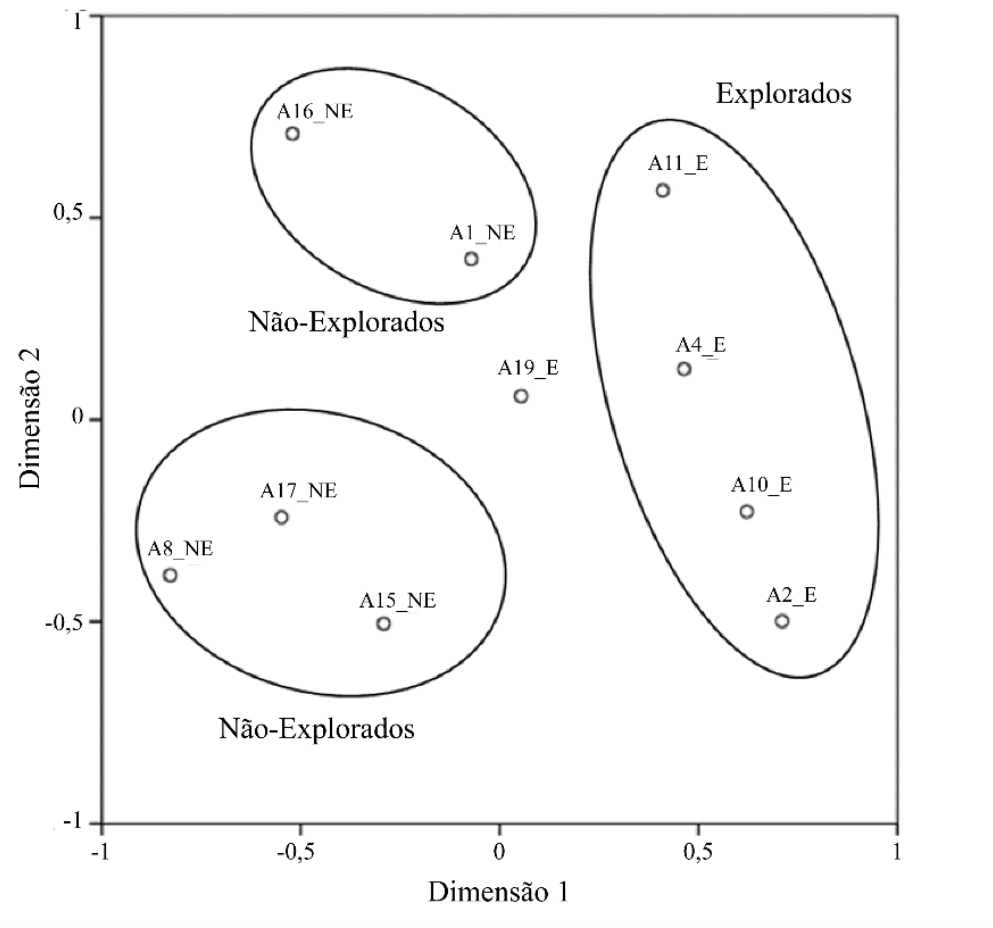

Figura 3. Representação gráfica de indivíduos de Hevea brasiliensis explorados e não-explorados pela análise de Escalonamento Muldimensional.

Figure 3. Graphical representation of tapped and untapped Hevea brasiliensis trees by Multidimensional Scanling technique.

\section{DISCUSSÃO}

De maneira geral, as árvores exploradas e não-exploradas apresentaram características qualitativas semelhantes, condizentes com a literatura. Entre as principais características, podem ser destacadas: porosidade 
difusa; placa de perfuração simples; presença de tilos; presença de cristais; parênquima axial em faixas estreitas; parênquima reticulado; raios largos e multisseriados; entre outras (INSIDE WOOD, 2004).

Maiores diferenças entre os grupos analisados foram observadas nas características anatômicas quantitativas. Foram observadas diferenças estatísticas significativas entre algumas variáveis analisadas pelo teste de Mann-Whitney. Os indivíduos explorados apresentaram maiores médias para a comprimento de fibra, espessura de parede das fibras, frequência de vasos, largura de raios, altura de raios e proporção de fibras não-gelatinosas.

As diferenças nas características quantitativas do lenho entre os dois grupos de árvores estudados foram suficientes para que esses grupos pudessem ser reconhecidos e divididos pela análise Two Step Cluster. A exploração dos dados no EMD demonstrou padrão parecido com o padrão apresentado pela Two Step Cluster na divisão dos grupos. Essa resposta pode indicar que a exploração do látex influencia nas características do xilema.

A largura de raios foi a característica mais importante na diferenciação dos grupos pela Two step Cluster. Os raios, assim como o parênquima axial, correspondem à porção viva no xilema secundário, entremeado com o tecido não-vivo, isto é, as fibras e os elementos de vaso (MORRIS; JANSEN, 2016). Dentre suas funções, podem ser citados: armazenamento de transporte de carboidratos não-estruturais (CNE) (SILPI et al., 2006; SILPI et al., 2017; FONTI et al., 2015; MORRIS et al., 2016); defesa contra patógenos; armazenamento de minerais; reforço biomecânico; e armazenamento e transporte de água, assim como os elementos de vaso (MORRIS et al., 2016). As proporções de raios em folhosas costumam variar de 10 a $20 \%$, enquanto o parênquima axial pode variar de 1 a 30\% (PLAVCOVÁ; JANSEN, 2015). O volume de tecido parenquimático pode ser considerado como um compartimento disponível para armazenamento de substâncias, das quais os CNE são as mais abundantes (PLAVCOVÁ; JANSEN, 2015).

Sabe-se que as plantas são capazes de responder a fatores externos de natureza diversa, com alterações no lenho. Por exemplo, plantas que sofreram ferimento cambial podem apresentar alterações no parênquima, vasos e raios (MYBURG; SEDEROFF, 2001; ARBELLAY et al., 2012). A injúria do câmbio induz a formação de elementos de vaso mais estreitos e de menor frequência, voltando a aumentar quando o lenho se normaliza. Os resultados do trabalho de Arbellay et al. (2012) com Faxinus excelsior L. demonstram essa plasticidade do xilema em responder a estímulos. Os autores observaram, ainda, aumento do número de raios nos anéis de crescimento localizados após a injúria, aumentando em direção à margem do ferimento, bem como aumento na iniciação dos raios com pelo menos três anos após a cicatrização.

A diferença na proporção de fibras gelatinosas também foi um resultado interessante. Fibras gelatinosas são características do lenho de seringueira (NOBUCHI et al.; RAMOS et al., 2016). As seringueiras nativas, no entanto, apresentaram fibras gelatinosas em menor proporção do que observado por Ramos et al. (2016) em estudo com seringueiras cultivadas. As fibras gelatinosas são características de lenho de tração, cuja função é reorientar troncos e ramos, reforçar pontos de tensão e realizar manutenção dos ângulos de ramos (HUNG et al., 2016; GROOVER, 2016). Esse fenômeno ocorre em resposta à estímulos ambientais e gravitacionais (HUNG et al., 2016), visando reforçar ou reorientar troncos e ramos (GROOVER, 2016). Sua composição morfológica e química difere notavelmente do lenho normal (LEHRINGER et al., 2009). Esse tipo diferenciado de fibra apresenta uma camada interna à camada $S_{2}$, chamada camada gelatinosa, caracterizada por altos níveis de celulose cristalina e por baixo ângulo microfibrilar, próximo a $0^{\circ}$ (DÉJARDIN et al., 2010).

Seringueiras cultivadas apresentam maiores proporções de fibras gelatinosas (NOBUCHI et al., 2011; RAMOS et al., 2016). Ramos et al. (2016) estudaram a anatomia do lenho de tração em clones de seringueiras e observaram proporções de fibra gelatinosa variando de 38 a 51\%. Nas árvores nativas estudadas no presente trabalho, as proporções dessas fibras gelatinosas variaram de 4\% (árvores exploradas) a 13\% (árvores nãoexploradas). As condições às quais seringueiras nativas e cultivadas são submetidas podem ser a chave para explicar essa diferença. Seringueiras cultivadas são plantas enxertadas, algumas vezes tricompostas (cavalo, enxerto de caule e enxerto de copa), o que pode causar desequilíbrio da copa, levando ao deslocamento do tronco em relação ao eixo natural da planta. Seringueiras nativas, por sua vez, crescem e se desenvolvem naturalmente, sendo assim menos suscetíveis a esse tipo de desequilíbrio.

No processo de biossíntese da camada gelatinosa no lenho de tração em desenvolvimento, há uma série de genes expressos, envolvidos na reprogramação do metabolismo de carboidrato, o que resulta no aumento das atividades para biossíntese da celulose e degradação de pectina (ANDERSSON-GUNERAS et al., 2006). Portanto, pode-se pensar que a extração do látex pode reduzir o desenvolvimento das fibras gelatinosas devido ao desvio de fotoassimilados durante a regeneração do fluxo de látex, o que pode limitar a diferenciação desses elementos do xilema bem como a síntese dos componentes da parede celular.

A extração do látex é realizada com cuidado para que o câmbio não seja atingido, de maneira a não ferir e prejudicar sua atividade. No entanto, a regeneração do fluxo de látex após extração é uma atividade que apresenta alta demanda de fotoassimilados. De fato, quando a árvore é sangrada, a casca é ferida e parcialmente removida, 
persistindo no painel de sangria o câmbio e o floema jovem. Consequentemente, a translocação de assimilados vindos da copa é parcialmente obstruído (SILPI et al., 2006). Ao induzir a regeneração do látex, a sangria desvia uma proporção significativa de fotoassimilados (SILPI et al., 2007).

A sensibilidade da seringueira à extração de látex foi comprovada em alguns estudos. Numa avaliação da dinâmica de crescimento de seringueiras extraídas e não-extraídas, Silpi et al. (2006) observaram que o crescimento de plantas sangradas foi similar ao das plantas controle no período de descanso (intervalo entre as sangrias). Quando a sangria foi retomada, observou-se uma forte diminuição da taxa de crescimento radial durante todo o período exploratório, com o crescimento das plantas sangradas em torno da metade do crescimento das plantas controle, culminando num déficit cumulativo de $80 \%$ para o período vegetativo. Esses resultados demonstram que o crescimento e regeneração do látex competem por carbono e, segundo os autores do estudo, corroboram que a regeneração do látex tem preferência. Segundo Silpi et al. (2007), como a sangria envolve ferimentos repetitivos, além de precisarem regenerar o látex, as plantas também passam por estresse, aumentando a taxa respiratória e o uso de carboidrato.

\section{CONCLUSÕES}

Os resultados obtidos permitem concluir que:

- A extração de látex influencia nas características quantitativas do lenho de seringueiras.

- As diferenças entre os indivíduos explorados e não-explorados são observadas na largura de raios, comprimentos e largura de fibra, espessura de parede das fibras, altura de raios, frequência e diâmetro dos elementos de vaso, e proporções de fibras normais, fibras gelatinosas e parênquima axial.

- Os indivíduos explorados apresentaram raios mais largos e mais altos, sendo a largura de raios a variável mais importantes na divisão dos grupos segundo a análise estatística. Esse resultado é um importante indício da necessidade da planta em aumentar o volume de armazenamento de carboidratos para uso conforme a necessidade.

- Árvores exploradas apresentaram menor proporção de fibras gelatinosas do que árvores não-exploradas. Isso pode ser atribuído ao desvio de fotoassimilados para a regeneração do látex após sua extração, o que pode limitar a diferenciação dos elementos do xilema.

- Recomendam-se, portanto, estudos acerca do consumo de carboidratos não-estruturais, relacionados diretamente com as mudanças na estrutura do xilema de seringueira nativa quanto de seringueira cultivada, bem como estudos acerca do metabolismo na formação do lenho de tração em seringueiras.

\section{AGRADECIMENTOS}

Os autores agradecem à Universidade Federal do Acre e ao Prof. Moisés Lobão pelo suporte logístico para a coleta do material lenhoso, e a CAPES pela concessão da bolsa de Doutorado à primeira autora.

\section{REFERÊNCIAS BIBLIOGRÁFICAS}

ANDERSSON-GUNNERÅS, S.; MELLEROWICZ, E. J.; LOVE, J.; SEGERMAN, B.; OHMIYA, Y.; COUTINHO, P. M.; NILSSON, P.; HENRISSAT, B.; MORITZ, T.; SUNDBERG, B. Biosynthesis of celluloseenriched tension wood in Populus: global analysis of transcripts and metabolites identifies biochemical and developmental regulators in secondary wall biosynthesis. The Plant Journal, v. 45, n. 2, p. 144-165, 2006.

ARBELLAY, E.; P. FONTI, P.; STOFFEL, M. Duration and extension of anatomical changes in wood structure after cambial injury. Journal of Experimental Botany, v. 63, p. 3271-3277, 2012.

BRASIL. Decreto n. 5.975, de 30 de nov. de 2006. Brasília, DF, novembro de 2006. Disponível em: <http://www.planalto.gov.br/ccivil_03/_ato2004-2006/2006/decreto/d5975.htm. /> Acesso em: 22 Nov. 2017.

BUKATSCH, F. Bemerkungen zur Doppelfärbung Astrablau-Safranin. Mikrokosmos, Sttutgart, v.61, n.8, p.255, 1972.

DÉJARDIN, A.; LAURANS, F.; ARNAUD, D.; BRETON, C.; PILATE, G.; LEPLÉ, J. C. Wood formation in Angiosperms. Comptes Rendus Biologies, n. 333, p. 325-334, 2010.

EVERT, R. F. Esau's plant anatomy, Meristems, cells, and tissues of the plant body: their structure, function, and development, 3rd edn. Hoboken, NJ: John Wiley \& Sons, Inc. 2006.

FLORESTA, Curitiba, PR, v. 48, n. 2, p. 255-264, abr/jun 2018

Ramos. L. M. A et.al.

ISSN eletrônico 1982-4688

DOI: $10.5380 /$ rf.v48 i 2.55584 
FONTI, P.; TABAKOVA, M. A.; KIRDYANOV, A. V.; BRYUKHANOVA, M. V.; ARX, G. von. Variability of ray anatomy of Larix gmelinii along a forest productivity gradient in Siberia. Trees, v. 29, p. 1165-1175, 2015.

GROOVER, A. Gravitropisms and reaction woods of forest trees-evolution, functions and mechanisms. New Phytologist, v. 211, n. 3, p. 790-802, 2016.

HUNG, L. F.; TSAI, C. C.; CHEN, S. J.; HUANG, Y. S.; KUO-HUANG, L. L. Study of tension wood in the artificially inclined seedlings of Koelreuteria henryi Dummer and its biomechanical function of negative gravitropism. Trees, v. 30, n. 3, p. 609-625, 2016.

InsideWood. 2004. Publicado na internet. Disponívem em: <http://insidewood.lib.ncsu.edu/search〉. Acesso em 29 Ago. 2017.

JUNJITTAKARN, J.; LIMPINUNTANA, V.; PANNENGPETCH, K.; AYUTTHAYA, S. I. N.; ROCHETEAU, A.; COCHARD, H.; DO, F. Short term effects of latex tapping on micro-changes of trunk girth in Hevea brasiliensis. Australian Journal of Crop Science. V. 6, n. 1, p. 65-72, 2012.

LEHRINGER, C.; DANIEL, G.; SCHMITT, U. TEM/FE-SEM studies on tension wood fibres of Acer spp., Fagus sylvatica L. and Quercus robur L. Wood Science and Technology, n. 43, p. 691-702, 2009.

MORRIS, H.; JANSEN, S. Secondary xylem parenchyma-from classical terminology to functional traits. IAWA Journal, Leiden v. 37, p. 1-13, 2016.

MORRIS, H.; PLAVCOVÁ, L.; CVECKO, P; FICHTLER, E; GILLINGHAM, M. A. F.; CABRERA, H. I. M.; MCGLINN, D. J.; WHEELER, E.; ZHENG, J.; ZIEMINSKA, K.; STEVEN JANSEN, S. A global analysis of parenchyma tissue fractions in secondary xylem of seed plants. New Phytologist, v. 209, n. 4, p. 1553-1565, 2016.

MYBURG, A. A.; SEDEROFF, R. R. Xylem Structure and Function. Enciclopedia of Life Sciences, 2001.

NAKABA, S.; MORIMOTO, H.; ARAKAWA, I.; YMAGISHI, Y.; NAKADA, R.; FUNADA, R. Responses of ray parenchyma cells to wounding differ between earlywood and latewood in the sapwood of Cryptomeria japonica. Trees, v. 31, n. 1, p. 27-39, 2016.

NOBUCHI, T.; MUNIANDY, D.; SAHRI, M. H. Formation and anatomical characteristics of tension wood in plantation-grown Hevea brasiliensis (Willd.) Muell.-Arg. Malaysian Forester, Kuala Lumpur, v. 74, n. 2, p. 133$142,2011$.

PLAVCOVÁ, L.; JANSEN, S. The role of xylem parenchyma in the storage and utilization of nonstructural carbohydrates. In: Functional and ecological xylem anatomy. Springer International Publishing Switzerland, p. 209-234, 2015.

RAMOS, L. M. A.; LATORRACA, J. V. D. F.; CASTOR NETO, T. C.; MARTINS, L. S.; SEVERO, E. T. D. Anatomical characterization of tension wood in Hevea brasiliensis (Willd. ex A. Juss.) Mull. Arg. Revista Árvore, Viçosa, v. 40, n. 6, p. 1099-1107, 2016.

SAFFIAN, H. A.; TAHIR, P. M.; HARUN, J.; JAWAID, M.; HAKEEM, K. R. Influence of planting density on the fiber morphology and chemical composition of a new latex-timber clone tree of rubberwood (Hevea brasiliensis Muell. Arg.). BioResources, Raleigh, v. 9, n. 2, p. 2593-2608, 2014.

SEVERO, E. T. D.; OLIVEIRA, E. F.; SANSIGOLO, C. A.; ROCHA, C. D.; CALONEGO, F. W. Properties of juvenile and mature woods of Hevea brasiliensis untapped and with tapping panels. European Journal of Wood and Wood Products, v. 71, n. 6, p. 815-818, 2013.

SILPI, U.; THALER, P.; KASEMSAP, P.; LACOINTE, A.; CHANTUMA, A.; ADAM, B.; GOHET, E.; THANISAWANYANGKURA, S.; AMÉGLIO, T. Effect of tapping activity on the dynamics of radial growth of Hevea brasiliensis trees. Tree physiology, Victoria, v. 26, n. 12, p. 1579-87, dez. 2006.

SILPI, U; LACOINTE, A.; KASEMPSAP, P; THANYSAWANYANGKURA, S.; CHANTUMA, P.; GOHET, E.; MUSIGAMART, N.; CLÉMENT, A.; AMÉGLIO, T.; THALER, P. Carbohydrate reserves as a competing sink: evidence from tapping rubber trees. Tree Physiology, Victoria, v. 27, p. 881-889, 2007.

WHEELER, E. A.; BAAS, P.; GASSON, P. E. (Ed.). IAWA list of microscopic features for hardwood identification. Leiden, 1989. 